AC 2009-2475: THE RELATIVE IMPORTANCE OF GENDER, MAJOR, YEAR, AND COHORT DIFFERENCES IN UNDERGRADUATE ENGINEERING ORIENTATIONS

Moshe Hartman, Retired

Harriet Hartman, Rowan University 
AC 2009-2475: THE RELATIVE IMPORTANCE OF GENDER, MAJOR, YEAR AND COHORT DIFFERENCES IN UNDERGRADUATE ENGINEERING ORIENTATIONS

Moshe Hartman, Retired

Harriet Hartman, Rowan University 


\section{The Relative Importance of Gender, Major, Year and Cohort Differences in Undergraduate Engineering Orientations}

Recent studies have shown that while there are relatively minor differences in the pre-college qualifications of men and women recruited to engineering, gender differences persist in engineering self-confidence, satisfaction with engineering programs, expectations from an engineering degree, academic achievement in engineering, commitment to a future in engineering $^{[5]}$. Further, these gender differences vary over the undergraduate year. For example, first-year women have much lower engineering self-confidence than entering men; while junior women and men have been shown to be much more similar in engineering self-confidence (women's is higher than it was in their first-year; men's is leveled by their experiences in the engineering program $)^{[4]}$. Anecdotally, we all have experience with cohorts with different temperaments: sometimes a cohort of students assumes a critical identity, showing dissatisfaction with many aspects of a program, even though the program itself has not changed; sometimes a cohort shows gender tensions which persist throughout their tenure in the program. Finally, previous research has shown that both men and women vary in their engineering orientations by engineering discipline. They vary in their perceived strengths in engineering, which is related to their satisfaction with engineering as a suitable fit for them; students in some majors emphasize the monetary rewards that will come when they graduate, while others place more importance on their contribution to the societal good. ${ }^{[6]}$ The ways in which the genders vary in the respective disciplines is of particular interest, as it may give us a clue as to why so few women enter certain disciplines and are attracted to others disproportionately ${ }^{[1,10]}$. Further, in at least one study, gender differences in engineering GPA's (women's being higher) disappeared when major was controlled $^{[7]}$. In other words, sometimes observed gender differences are artifacts or inflated because of the differential distribution of the genders across engineering disciplines. We envisioned writing a paper entitled, "It's the Major, Stupid!" But it isn't that simple, as our data show. Gender matters, and major matters, and year in the program matters, and they even interact in instructive ways.

The question posed in this paper is how persistent are gender differences in engineering orientation and achievement, once we control for engineering discipline, cohort, and year in the program. More specifically, we ask:

1. Do gender differences persist in grades, engineering self-confidence, satisfaction with engineering major, satisfaction with peers, and commitment to engineering as a career, even when major, year, and cohort are controlled?

2. Is there an interaction between gender and major, so that women and men in the same major have different reactions/achievements in engineering?

3. How much variation in these variables is there between majors (women or men)?

4. Is there a clear pattern of variation in any of these variables as students progress through their undergraduate program?

5. How much variation is there from year to year, or from cohort to cohort?

Data

Data were taken from surveys collected during an ongoing study of all engineering students in the university during the years $2002-2008^{\mathrm{i}}$ at a mid-Atlantic public university. During each of these years, students were administered one survey at the beginning of the fall semester and one 
at the end of the following spring semester. The data reported in this paper are taken from the responses to the spring surveys of students which queried attitudes toward engineering, selfconfidence in engineering, satisfaction with the major and the career, commitment to a future in engineering, and expectations from a degree in engineering, among other topics. This study is exemplary in its inclusion of over $85 \%$ of the students in any given semester, as surveys were distributed in required courses. Because both men and women are surveyed, differences between genders as well as differences between majors or other characteristics of students can be compared across genders.

The engineering college has four engineering disciplines: chemical, civil/environmental, electrical/computer, and mechanical. These disciplines vary by proportion of women, and sometimes that proportion varies considerably by cohort as well (Table 1).

Table 1

Percentage of Women Students in Major by Year of Survey (n)

\begin{tabular}{|l|l|l|l|c|}
\hline & Chemical & Civil/environmental & Electrical/computer & Mechanical \\
\hline Spring 2002 & $26.7(60)$ & $29.7(74)$ & $4.7(107)$ & $13.4(97)$ \\
\hline Spring 2003 & $35.5(62)$ & $23.1(52)$ & $8.2(97)$ & $10.2(127)$ \\
\hline Spring 2004 & $29.2(65)$ & $29.3(75)$ & $6.3(95)$ & $11.0(109)$ \\
\hline Spring 2005 & $31.6(76)$ & $15.0(80)$ & $7.4(81)$ & $9.6(94)$ \\
\hline Spring 2006 & $28.8(73)$ & $11.8(85)$ & $4.5(66)$ & $11.0(91)$ \\
\hline Spring 2007 & $28.2(85)$ & $16.1(87)$ & $7.2(69)$ & $9.7(93)$ \\
\hline Spring 2008 & $31.6(76)$ & $11.9(84)$ & $4.2(72)$ & $15.7(102)$ \\
\hline Total \% (n) & $31.4(497)$ & $19.0(537)$ & $6.1(587)$ & $11.5(713)$ \\
\hline
\end{tabular}

Controlling for major and survey year effectively controls for the proportion of women in the student's immediate cohort.

Our dependent variables are:

Engineering grades: Students self-reported their grade point average (GPA) in their engineering courses.

Engineering self-confidence: Students rated themselves in terms of how well they thought they fit in engineering, by the extent to which they agreed (on a 5-point scale from strongly disagree to strongly agree) with statements about how well-suited they were for their choice of college major and chosen career, whether they considered themselves mechanically inclined, technically inclined, good at designing things, and whether they felt competent in the skills required for their major. These items were factor-analyzed using a principal components factor analysis, and were found to load on one factor, which explained 62.8\% of the variance (Chronbach $\alpha=.879$ ). The overall mean of the factor score is 0 , with lower scores indicating less self-confidence, and higher scores indicating greater self-confidence.

Satisfaction with the core engineering course: Because all students are required to take a common core course each semester, and this forms a foundational part of this engineering program, we focused on the students' satisfaction with this course, on a scale of 1-5 from 
strongly disagree to strongly agree. Since teamwork is at the foundation of this course ${ }^{[1]}$, it is of particular interest in terms of gender; teamwork is widely considered to be the favored pedagogy of women as compared to men ${ }^{[11]}$, and yet teamwork can at times work to women's

disadvantage ${ }^{[2]}$ Two factors resulted from the factor analysis of 7 items, and we focused on the first factor which explained $37.5 \%$ of the variance in the items (Chronbach $\alpha=.824)$. The five items with high loading on this factor were: the course provides realistic experiences like in the work world; the course provides useful hands-on experiences; the interdisciplinary nature of the course enables me to connect things from different disciplines; the course unifies students in the same class but from different majors; and overall the course experience is beneficial. The overall mean of the factor score is 0 , with lower scores indicating less satisfaction, and higher scores indicating greater satisfaction.

Satisfaction with peers: Students rated their agreement (on a 5-point scale from strongly disagree to strongly agree) with a series of 13 statements about their peers. These items were factoranalyzed using a principal components factor analysis with Varimax rotation. The first factor, explaining $57.8 \%$ of the variance (Chronbach $\alpha=.905)$ in the statements, was used. Items with high loading on this factor include: engineering students are approachable, supportive, friendly, help each other, listen, respect me, care about me, are proud to be engineering students, and feel a sense of community in the engineering college. The overall mean of the factor score is 0 , with lower scores indicating less satisfaction with peers, and higher scores indicating greater satisfaction with peers.

Expectations: We focused on three types of expectations students had about the type of job their degree would allow: getting a well-paying job, associating with interesting people, and being an important contributor to society. For each, students recorded their agreement with the statement from $1=$ strongly disagree to $5=$ strongly agree.

Commitment to the engineering career: we focused on the responses to the question of whether the student expected to be working as an engineer ten years from now (the survey date). Students responded on a 5-point scale from 1 (very unlikely) to 5 (very likely). We had also asked the highest degree the student expected to achieve in engineering, but found that this varied by discipline and reflected less the degree of long-term commitment to engineering and more the norms of that discipline in terms of how much training was rewarded or expected before getting a good job in the labor force.

All factor analyses were performed using the principal components Varimax rotation method. Analysis verified that the factors that emerged were identical in content between the genders, and over the years of the program. The reliability test was also performed over multiple groups to make sure that the index worked similarly for all subgroups in the analysis.

Our independent variables are:

Gender:1=men; 2=women.

Year in the program: from 1=first-year to $4=$ =senior. 
Major: chemical, civil/environmental, electrical/computer; mechanical. Students are encouraged to select a major already in their first year, and there is relatively little switching during the course of the undergraduate years. Every semester of the survey, students were asked whether they had changed majors from the previous semester. Less than 5\% of the women and 7\% of the men reported changing majors within engineering, and even fewer entered from non-engineering majors.

Term of Survey: Because slight changes have occurred in the program over the years, we also introduced a control for the term the data was collected. By controlling for term in the analysis of variance, we also effectively control for the bias presented by having some of the same students in the sample for different years of the program. That is, mechanical engineering majors who began their program in 2002 as first-year students were sophomores in 2003, juniors in 2004, and seniors in 2005. If we did not control for the year in which the data was collected, we would be analyzing some of the same students four times. The model allows us to draw conclusions about whether, in any particular term (i.e., keeping term of the survey constant), year in the program affects our dependent variable. It also allows us to test whether the variation in the program (represented by term of survey) affects the dependent variable, or interacts with any of the other independent variables (gender, major, year in the program) in their relationship with the dependent variables. Alternatively, we could analyze each year in the program separately, but this would eliminate the opportunity to analyze how important year in the program was as an effect on any of our dependent variables. Or we could follow a particular cohort as they travelled through the program, and sometimes such an analysis is of interest (i.e., following a student's development in a longitudinal analysis). But in the present case, when we are attempting to tease out the relative importance of gender, major and year in the program, including the same student more than once might bias the results (e.g., for certain students, gender might make more of a difference in their attitudes than for others).

Method: We realized that we needed a complex model that would handle the variations by gender, discipline, and year in the program in order to determine which explained the greatest variation once the others were controlled. We needed a method that would be able to control for the year the survey was administered, so that the presence in multiple years of the survey by any particular student would not bias the results. Not all of the independent variables could be ordered linearly (there was no a priori reason to expect one major to be more satisfied with engineering than another, for example, or to have higher/lower grades than another), and we wanted to check for interactions between the independent variables. Our method of choice was therefore analysis of variance. This method tells us the net effect of each of our dependent variables once the other variables have been controlled. For example, whether gender differences in engineering GPA are significant when we control for major, year in the program, and cohort; whether major differences in engineering GPA are significant when we control for gender, year in the program and cohort; and so on. It does not assume a linear effect of the independent variables, but actually shows us which of the categories are significantly different from others, and in what way. It also tells us whether the interaction of gender and major, for example, is significant: whether major makes more or less of a difference for men and women's GPA. Examining the mean GPA's will tell us more about how this interaction affects GPA.

Results 
Academic Achievement (Engineering grades): Women have significantly higher engineering grades than men (mean engineering GPA of 3.40 compared to men's 3.23), even after we control for major, year in the program, and cohort (Table 2). There is a wider range in women's grades over major, however, resulting in a slight interaction (statistically significant only at $\mathrm{p}<.10$ ) between gender and major in terms of grades: women's grades range from a low average of 3.27 in mechanical engineering to a high average of 3.52 in chemical engineering; men's grades have a narrower range from an average of 3.14 in civil engineering to 3.29 in chemical engineering.

Grades are higher among first-year students, lowest for sophomores, and then higher in the junior and senior years (though not as high as first-year). This pattern for the total is true for men but not for women; among women, grades are highest among first-year students and decline with each successive year. As a result, the widest gender gap in grades is among first-year students, with men's average engineering GPA 3.30 compared to women's, 3.52; and the narrowest gender gap in grades is among seniors, with men's average engineering GPA 3.26 and women's, 3.27 .

Table 2

Analysis of Variance of Engineering Grade Point Average (GPA)

\begin{tabular}{|c|c|c|}
\hline & $F(d f)$ & $\begin{array}{l}\text { Observed Means } \\
\text { (Adjusted Means) }^{\text {a }}\end{array}$ \\
\hline \multicolumn{3}{|l|}{ Main effects } \\
\hline Gender & $17.39(1)^{*}$ & \\
\hline Men & & $3.23(3.24)$ \\
\hline Women & & $3.40(3.39)$ \\
\hline Major & $6.07(3)^{*}$ & \\
\hline Chemical & & $3.36(3.34)$ \\
\hline Civil/environmental & & $3.18(3.18)$ \\
\hline Electrical/computing & & $3.23(3.24)$ \\
\hline Mechanical & & $3.27(3.28)$ \\
\hline Year in Program & $8.22(3)^{*}$ & \\
\hline First-year & & $3.33(3.34)$ \\
\hline Sophomore & & $3.18(3.18)$ \\
\hline Junior & & $3.22(3.21)$ \\
\hline Senior & & $3.29(3.29)$ \\
\hline \multicolumn{3}{|l|}{ Covariate } \\
\hline Term of survey & $2.76(1)$ & \\
\hline \multicolumn{3}{|l|}{ Two-way interactions } \\
\hline Gender x Major & $2.54(3)^{*}$ & \\
\hline Gender x Year & $.18(3)$ & \\
\hline Major x Year & $.57(9)$ & \\
\hline
\end{tabular}

${ }^{\mathrm{a}}$ Adjusted for other main effects and covariate (term of survey). $* p<.05$ 
Engineering Self-confidence: Undergraduate engineering women have significantly less confidence that they fit in engineering than do men (mean factor scores .129 for men and -.244 for women, $\mathrm{p}<.05$ ). Rather than this difference diminishing once major, year, cohort and grades are controlled, the difference actually widens (adjusted mean scores are .141 for men and -.308 for women, $\mathrm{p}<.05)($ Table 3). It explains almost as much variance in the factor scores as does grades (students who have higher grades are more confident that they belong in engineering) (Table 4).

Table 3

Analysis of Variance of Engineering Self-Confidence, Core Course Satisfaction, and Satisfaction with Peers (F(df))

\begin{tabular}{|r|c|c|c|}
\hline & $\begin{array}{l}\text { Engineering Self- } \\
\text { Confidence }\end{array}$ & Core Course Satisfaction & Satisfaction with Peers \\
\hline Main effects & & & \\
\hline Major & $4.57(3)^{*}$ & $4.97(1)^{*}$ & $0.07(1)$ \\
\hline Year in Program & $8.22(3)^{*}$ & $2.56(3)^{* *}$ & $0.75(3)$ \\
\hline Covariate & & $6.80(3)^{*}$ & $7.26(3)^{*}$ \\
\hline Term of survey & 1.53 & & 2.19 \\
\hline Engineering GPA & $46.57^{*}$ & $21.12^{*}$ & $5.37^{*}$ \\
\hline Two-way interactions & & 0.34 & $0.93(3)$ \\
\hline Gender x Major & $3.59(3)^{*}$ & & $0.23(3)$ \\
\hline Gender x Year & $1.39(3)$ & $1.62(3)$ & $0.93(9)$ \\
\hline Major x Year & $1.48(9)$ & $0.11(3)$ & \\
\hline
\end{tabular}

$* \mathrm{p}<.05 ; * * \mathrm{p}<.10$.

Table 4

Means (Observed and Adjusted) ${ }^{a}$ of Engineering Self-Confidence, Core Course Satisfaction and Satisfaction with Peers for Gender, Major, and Year in Program Observed Means (Adjusted Means) ${ }^{a}$

\begin{tabular}{|r|l|l|l|}
\hline & $\begin{array}{l}\text { Engineering Self- } \\
\text { Confidence }\end{array}$ & Core Course Satisfaction & Satisfaction with Peers \\
\hline Main effects & & & \\
\hline Gender & & $.000(.008)$ & $.048(.056)$ \\
\hline Men & $.129(.141)$ & $.210(.170)$ & $.077(.037)$ \\
\hline Women & $-.244(-.308)$ & & $.044(.045)$ \\
\hline Major Chemical & $-.024(.015)$ & $.068(.065)$ & $.099(.107)$ \\
\hline Civil/environmental & $.061(.097)$ & $.023(.029)$ & $-.010(.000)$ \\
\hline Electrical/computer & $-.015(-.043)$ & $-.083(-.074)$ & $.082(.067)$ \\
\hline Mechanical & $.217(.191)$ & $.120(.109)$ & $-.121(-.130)$ \\
\hline Year in Program & & & $.084(.096)$ \\
\hline First-year & $-.062(-.097)$ & $-.126(-.113)$ & $.143(.150)$ \\
\hline Sophomore & $.057(.090)$ & $.025(.026)$ & $.148(.140)$ \\
\hline Junior & $.116(.132)$ & $.144(.128)$ & $.128(.127)$ \\
\hline
\end{tabular}

${ }^{\mathrm{a}}$ Adjusted in analysis of variance for other main effects and covariates (term of survey, GPA). 
While less important than these two factors, both major and year in the program also show significant variation in engineering self-confidence. Mechanical engineering students are the most confident, followed by civil/environmental engineering majors; electrical/computing engineering majors are next; while chemical engineering students have the weakest engineering self-confidence. After controlling for gender, year in the program, and cohort, mechanical and civil engineering majors remain the most confident, and electrical/computer and chemical engineering majors the least confident.

There is, however, a significant interaction effect between major and gender. While both men and women mechanical engineering majors are the most confident in themselves as engineers, electrical engineering majors are the least confident among the men, but chemical engineering majors are the least confident among the women. Further, major makes more of a difference among women than among men. The gender gap in engineering self-confidence is especially large among chemical engineering majors (see Figure 1). It is narrowest among civil/environmental majors.

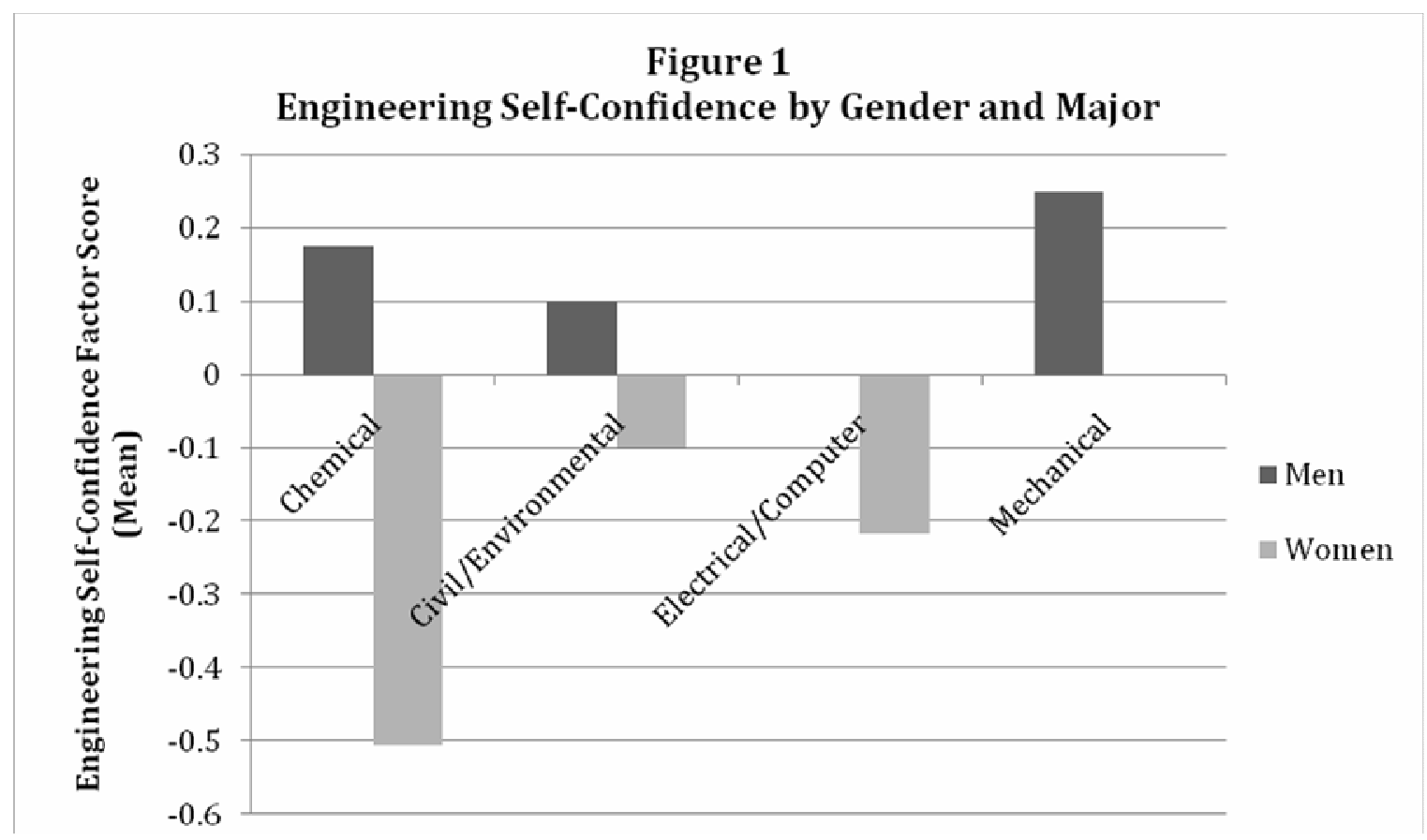

Students are increasingly confident in themselves as engineers as they progress through the undergraduate program, with first-year students' mean factor score being -.062 compared to seniors' .202. The pattern is much clearer for men than for women, however; among men, selfconfidence varies from -.032 among first-year students to .301 among seniors, $\mathrm{p}<.001$; among women, the variation over year is very small, ranging from -.278 to -.233, and not statistically significant. Partly this reflects non-linear fluctuation in women's engineering self-confidence: sophomore women's self-confidence is higher than first-year women's self-confidence, but women's self-confidence is lower among juniors and seniors than it is for sophomores. (Earlier analysis of the first year of the survey ${ }^{[4]}$ suggested that the decline in women's self-confidence occurred only in the senior year, but this aggregated data suggests that the decline occurs after the sophomore year.) 
The year of the survey, or the engineering cohort, is not significantly related to engineering selfconfidence.

Core course satisfaction: Women are more satisfied with the core engineering course than are men (Table 4), but this is not the most important factor explaining variation in course satisfaction (Table 3). More important is the year in the program, with upper division students being more satisfied than lower division students. There is little difference between junior and senior satisfaction, which is expectable, as juniors and seniors usually participate in the core course together. There is an interaction between major and year in the program in terms of satisfaction with the course: there is a greater variation between majors among seniors, with electrical/computer engineering seniors being least satisfied compared to the other majors; and less variation by major among first-year students (Figure 2). This may be related to the interdisciplinary nature of the first-year course, which intentionally mixes students from different majors. As the core courses in junior and senior years vary by discipline, the variation by major may reflect a difference in the way this discipline runs its upper division core course.

While junior and senior core courses may also be multi-disciplinary, the teams themselves are more homogeneous. The variation by discipline may reflect variation in the projects the students in more advanced years are working on or how they integrate with the other majors in the various years.

The year that the survey was taken makes a significant difference in satisfaction with the core course (Table 3). This may reflect changes that have been made to the core course between 2002-2008. Unfortunately, these changes may not sit well with students, as there is less satisfaction with the course in 2008 than there were in earlier years.

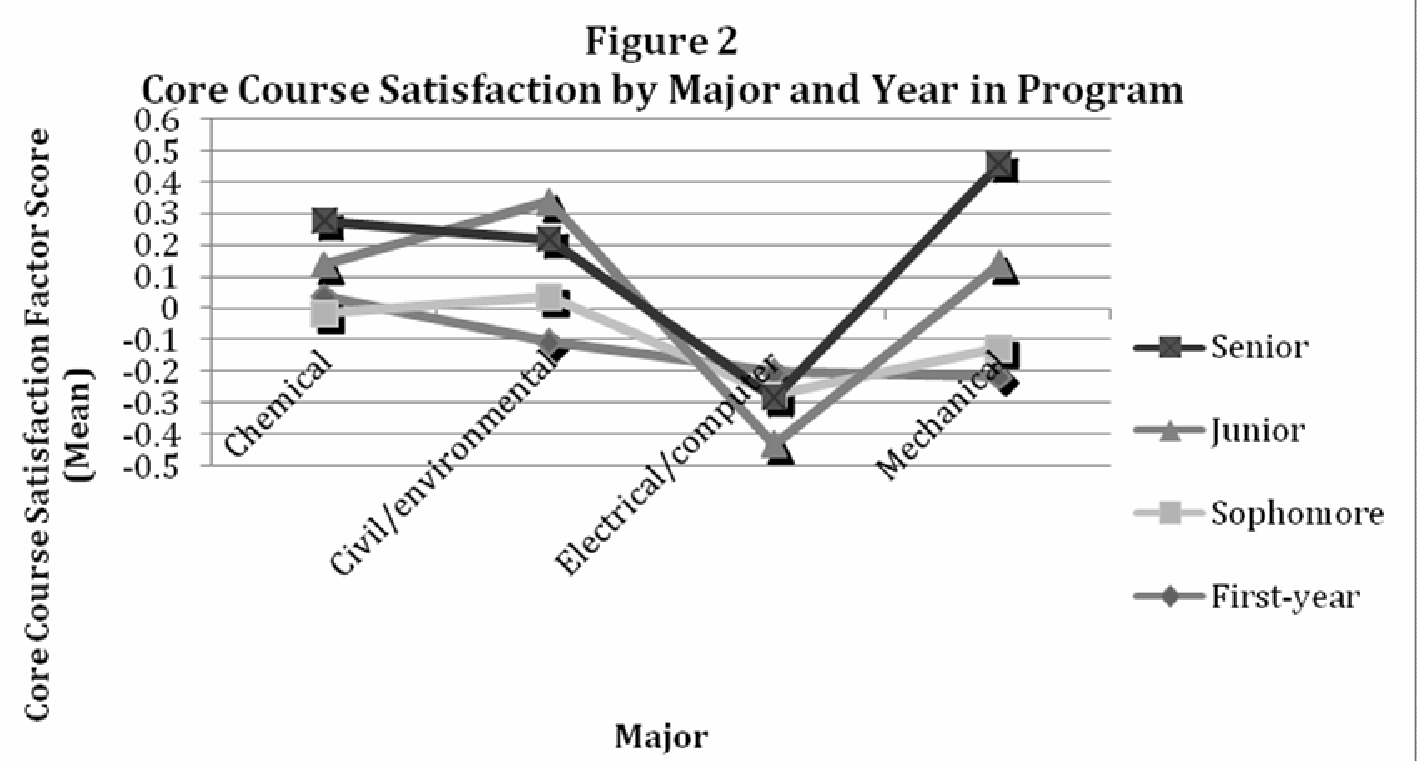


Satisfaction with Peers: There is no significant gender difference in terms of satisfaction with peers, once major, year in the program, grades, and survey year are controlled (Table 3 ). Both men and women feel equally positive about their peers. More important for explaining the variation in peer satisfaction is year in the program: the longer a student is in the program, the more positively they feel about their fellow students. This is true for men and women alike. Since cohorts in each of the majors travel through the program with their peers, solidarity builds as they encounter similar classes and projects. Apparently this camaradie is positive and contributes to a feeling of community with their peers. Also, students who have higher grades are more positive about their peers (or perhaps peer integration helps a student succeed academically).

\section{Expectations from the Engineering Degree:}

There is no gender difference in the expectation that engineering will enable a well-paying job or a job with interesting people, and there is no significant variation in major, year, or cohort either. Students with higher grades are more likely to expect a well-paying job, but that is the only significant source of variation between students (Table 5,6).

There is a slight tendency for women more than men to expect to be important contributors to society with an engineering degree, as well as for chemical and civil/environmental engineering majors to have higher expectations in this regard than do electrical/computer or mechanical engineers; while a higher proportion of women are in chemical and civil/environmental engineering, the effects of gender and major are independent (the interaction between them is not statistically significant with regard to expecting to make a contribution to society). Students with higher grades have higher expectations in this regard, as well.

Table 5

Analysis of Variance of Expectations after Engineering Degree and Long-term Commitment ( $\mathrm{F}(\mathrm{df}))$

\begin{tabular}{|c|c|c|c|c|}
\hline & $\begin{array}{l}\text { Expectations of } \\
\text { Good Pay }\end{array}$ & $\begin{array}{l}\text { Expectations of } \\
\text { Interesting People to } \\
\text { Associate With }\end{array}$ & $\begin{array}{l}\text { Expectations of } \\
\text { Making } \\
\text { Contribution to } \\
\text { Society }\end{array}$ & $\begin{array}{l}\text { Expect to be } \\
\text { Working as } \\
\text { Engineer in Ten } \\
\text { Years }\end{array}$ \\
\hline \multicolumn{5}{|l|}{ Main effects } \\
\hline Gender & $0.00(1)$ & $2.08(1)$ & $2.95(1)^{* *}$ & $3.96(1)^{*}$ \\
\hline Major & $1.64(3)$ & $0.75(3)$ & $1.80(3)$ & $0.90(3)$ \\
\hline Year in Program & $1.78(3)$ & $1.99(3)$ & $2.58(3)^{* *}$ & $3.02(3) *$ \\
\hline \multicolumn{5}{|l|}{ Covariate } \\
\hline Term of survey & 0.08 & 1.99 & 0.14 & $68.23 *$ \\
\hline Engineering GPA & $4.72 *$ & $3.72 *$ & $4.45^{*}$ & $4.16 *$ \\
\hline \multicolumn{5}{|l|}{$\begin{array}{l}\text { Two-way } \\
\text { interactions }\end{array}$} \\
\hline Gender x Major & $0.14(3)$ & $2.16(3)^{* *}$ & $1.91(3)$ & $2.54(3)^{* *}$ \\
\hline Gender x Year & $0.47(3)$ & $0.17(3)$ & $0.82(3)$ & $0.60(3)$ \\
\hline Major x Year & $1.06(9)$ & $0.97(9)$ & $1.05(9)$ & $2.05(9)^{*}$ \\
\hline
\end{tabular}

$* \mathrm{p}<.05 ; * * \mathrm{p}<.10$. 
Table 6

Means (Observed and Adjusted) ${ }^{\mathrm{a}}$ of Expectations after Engineering Degree and Long-term Commitment for Gender,

Major, and Year in Program

Observed Means (Adjusted Means) ${ }^{a}$

\begin{tabular}{|r|l|l|l|l|}
\hline & $\begin{array}{l}\text { Expectations of } \\
\text { Good Pay }\end{array}$ & $\begin{array}{l}\text { Expectations of } \\
\text { Interesting People to } \\
\text { Associate With }\end{array}$ & $\begin{array}{l}\text { Expectations of } \\
\text { Making } \\
\text { Contribution to } \\
\text { Society }\end{array}$ & $\begin{array}{l}\text { Expect to be } \\
\text { Working as } \\
\text { Engineer in Ten } \\
\text { Years }\end{array}$ \\
\hline Main effects & & & & \\
\hline Gender & & & $4.09(4.10)$ & $4.16(4.17)$ \\
\hline Wen & $4.45(4.45)$ & $3.87(3.87)$ & $4.22(4.19)$ & $4.02(3.99)$ \\
\hline Major & $4.48(4.45)$ & $3.95(3.95)$ & & $4.08(4.11)$ \\
\hline Chemical & $4.52(4.50)$ & $3.86(3.84)$ & $4.17(4.16)$ & $4.15(4.20)$ \\
\hline Civil/environmental & $4.52(4.50)$ & $3.91(3.91)$ & $4.16(4.17)$ & $4.23(4.19)$ \\
\hline Electrical/computer & $4.39(4.39)$ & $3.90(3.91)$ & $4.08(4.09)$ & $4.10(4.08)$ \\
\hline Yechanical & $4.40(4.41)$ & $3.85(3.85)$ & $4.07(4.06)$ & \\
\hline First-year & $4.53(4.52)$ & $3.86(3.86)$ & & $4.05(4.04)$ \\
\hline Sophomore & $4.50(4.51)$ & $3.93(3.94)$ & $4.17(4.19)$ & $4.11(4.08)$ \\
\hline Sunior & $4.39(4.40)$ & $3.86(3.87)$ & $4.18(4.19)$ & $4.31(4.32)$ \\
\hline
\end{tabular}

${ }^{\mathrm{a}}$ Adjusted in analysis of variance for other main effects and covariates (term of survey, GPA).

\section{Commitment to the Engineering Profession}

Men are more likely than women to anticipate working as an engineer ten years after college; this gender gap persists even when year, major, grades, and cohort are controlled (Tables 5,6). The relationship between major and commitment to working as an engineer is different for men and women. Women majoring in civil/environmental engineering are the women most likely to expect to be working as an engineer ten years later; in fact they are the most likely of any of the engineering students to express this long-term commitment. Men in this major are the least likely to express this commitment; it is men majoring in electrical/computer engineering who are the most committed among the male engineering students (Figure 3), and in all of the other majors, men are more likely to be committed to the engineering career than are women. 


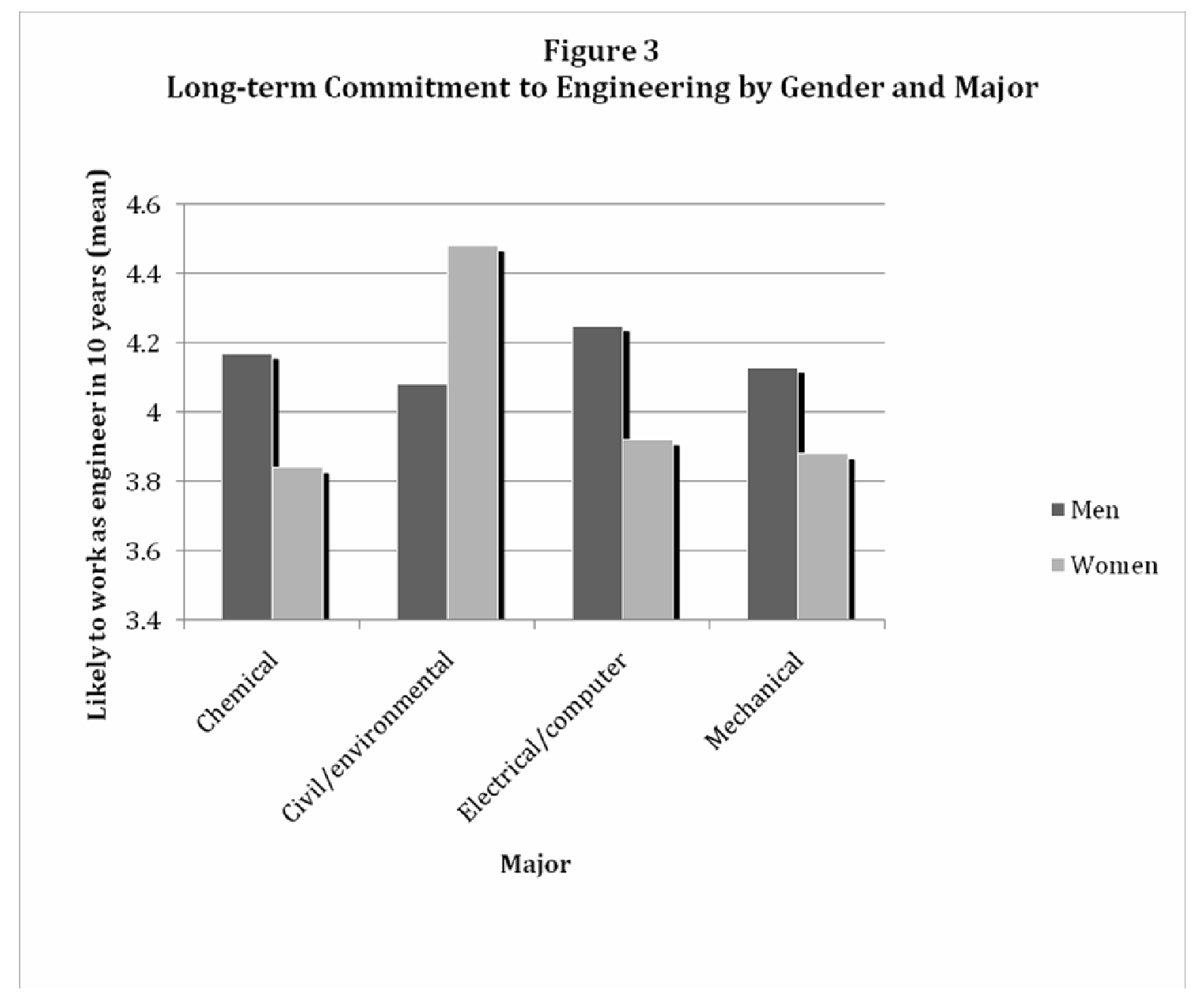

\section{Discussion}

With regard to our first research question, gender clearly matters with respect to engineering grades, self-confidence, satisfaction with the core course, and commitment to the engineering career, even when major, year, and cohort (and grades, for all of the other dependent variables) are controlled. This reinforces previous findings in the literature, which have not controlled for major and year in the program ${ }^{[9,12]}$. However, gender differences with regard to peer integration are insignificant; and there are few remaining gender differences with regard to expectations from an engineering degree.

More importantly, however, is our answer to our second research question, regarding the interaction between gender and major that is evident with regard to engineering self-confidence and long-term commitment to the career. Both of these variables are critical in terms of retaining women in the profession of engineering. The interaction does not follow the commonly expected lines of where women are more or less of a minority. Rather the gender gap in self-confidence is widest among chemical engineering majors (which overall have nearly a third of their students women). Women's self-confidence is highest among mechanical engineering majors, which has 
on average only $11.5 \%$ women; and this is the major which shows the highest proportion of women committed to working as an engineer in the long-term (at least ten years).

This reinforces the acknowledged need to better study gender (and other) dynamics within specific disciplines ${ }^{[8]}$, and apply lessons from the models of those disciplines which succeed in empowering women and garnering their long-term commitment to disciplines less successful in doing so.

More generally, it is clear that studying all engineering students as a whole misses some important points about the undergraduate experience. Engineering students recognize differences between the disciplines ${ }^{[13,14]}$; it's time that researchers recognize the importance of this source of variation, also.

Year in the program affects mainly satisfaction with the engineering program (in this case, the core course) and peers. These findings are not surprising; it is the most satisfied students who remain in engineering, and their cohort solidarity grows as they spend more time together. The lack of variation by cohort reinforces the validity of these findings and their generalizability to other settings.

The next important step would be to compare disciplines across undergraduate settings to determine whether the gender dynamics and other differences that we found are common to the discipline in all settings, or are particular to this particular program and setting. Either conclusion would lead to clear implications as to where it is most beneficial to work on empowering women and diminishing gender differences; and provide models of best inclusive practices that have long-term implications for retaining women in the profession. 
References

1. Farrell, Stephanie et. al. 2001.The Multidisciplinary engineering clinic at Rowan University: Benefits to Students and Faculty. Proceedings of the International Conference on Engineering Education, August, Oslo, Norway, Session 6E-7:16-20.

2. Felder, R.M. et al. 1995. A Longitudinal study of engineering student performance and retention. III. Gender differences in student performance and attitudes. Journal of Engineering Education 84(2): 151-174.

3. Gibbons, Michael T. 2006. The Year in Numbers. http://www.asee.org/publications/profiles/index.cfm\#The_Profiles_and_Data_Book. Retrieved 1/9/06.

4. Hartman, Harriet and Moshe Hartman. 2001. The role of self -confidence in undergraduate engineering education. Paper presented at the American Sociological Association meetings, Anaheim, California, August.

5. Hartman, Harriet and Moshe Hartman. 2003. Final Report to NSF: A Gender Lens on Rowan University's College of Engineering. Available online at: http://users.rowan.edu/ hartman/research.

6. Hartman, Harriet and Moshe Hartman. 2007.The gender impact in different engineering majors. Proceedings of the First International Conference on Research in Engineering Education. Hawaii, June.

7. Hartman, Moshe, Harriet Hartman, and Jennifer Kadlowec. 2008. The Impact of Bio-engineering: Part I. Do Bio-engineering students differ from other engineering students? Preliminary results. Proceedings of the American Association of Engineering Education Conference.

8. Jawitz, Jeff, and Leanne Scott.1997. Who does not succeed in engineering at the University of Cape Town? What can one tell from the retention rate? Proceedings of the $27^{\text {th }}$ Frontiers in Education Conference, v. 1, pp. 71-75.

9. Margolis, J., and Fisher, A. 2002. Unlocking the Clubhouse: Women in Computing. Cambridge, MA: MIT Press.

10. National Science Foundation. 2007. Women, Minorities, and Persons with disabilities in Science and Engineering: 2007. Arlington, VA: NSF: Division of Science resources Statistics, Publication NSF 07315.Table C-5. Available from http://www.nsf.gov/statistics/wmpd.

11. Rosser, Sue V., 1991. Female Friendly Science. Columbia, NY: Teacher's College Press.

12. Seymour, E.Y. and Hewitt, N.M. 1997. Talking about Leaving: Why Undergraduates Leave the Sciences. Colorado: Westview Press.

13. Shivy, Victoria and Terri Sullivan. 2003. Engineering students' perceptions of engineering specialties. Journal of Vocational Behavior 67(1): 87-101.

14. Trytten, Deborah, Susan Walden, Teri Reed Rhoads. "Industrial Engineering Student Perceptions of Computer Science, Computer Engineering, and Electrical Engineering. ASEE/IEEE Frontiers in Education Conference 2005 Oct Indianapolis. SIH-1-6 
${ }^{\mathrm{i}}$ The authors wish to acknowledge the helpful comments of Professor Jennifer Kadlowec, the support of the National Science Foundation, through Grant \#HRD-0074857; the University's Colleges of Engineering and Liberal Arts and Sciences; and the Department of Sociology. We are especially grateful to the engineering faculty's cooperation in allowing the surveys to be administered during class time. Needless to say, all responsibility for the contents of the paper and the conclusions from the research remains solely with the authors. For more information on the larger study, see ${ }^{[5]}$. 